\title{
Renewable resource-based poly(dodecyloate) by carbonylation polymerization $\dagger$
}

\author{
Dorothee Quinzler and Stefan Mecking*
}

\author{
Received (in Cambridge, UK) 23rd June 2009, Accepted 30th July 2009 \\ First published as an Advance Article on the web 14th August 2009 \\ DOI: $10.1039 / \mathrm{b} 912294 \mathrm{j}$
}

Cobalt-catalyzed step growth polymerization of undec-10-en-1-ol and $\mathrm{CO}$ affords aliphatic polyesters $\left(M_{\mathrm{n}}>10^{4} \mathrm{~g} \mathrm{~mol}^{-1}\right)$ based entirely on renewable resources.

Thermoplastic polymers are currently prepared almost exclusively from fossil feedstocks. In view of their limited range, alternative renewable resources are desirable in the long term. 'By comparison to routes employing a fermentation step, chemical synthetic routes in which the original molecular structure of the plant biomass employed is substantially retained are attractive as they can be efficient in terms of feedstock utilization and reaction space-time-yields, and provide novel properties. Polyesters are one of the most important classes of organic polymers, and indeed the more recently developed and commercialized biomass-based polymers are thermoplastic polyesters. ${ }^{2}$ Their preparation employs a fermentation step, with carbohydrates, most often glucose, as a feedstock.

We now report on the preparation of poly(dodecyloate) based on castor oil, a readily available ${ }^{3}$ plant seed oil ${ }^{4}$ industrial utilization of which does not compete with use as food. The major component of castor oil is ricinoleic acid (up to $95 \%$; as the triglyceride), which is converted in two high conversion steps to undec-10-en-1-ol (1). ${ }^{5}$ Alkoxycarbonylation ${ }^{6}$ of an ()-unsaturated alcohol is a known route to the cyclic lactone by ring closure, ${ }^{7}$ but it can in principle also resemble an $\mathrm{AB}$ step growth polymerization. For 1 , reaction with $\mathrm{CO}$ catalyzed by $\mathrm{Pd}(\mathrm{II})$-salts modified with $\mathrm{PPh}_{3}$ has been noted to yield oligomers, without further details. ${ }^{8}$

A very high conversion of functional groups is a prerequisite to achieve substantial molecular weights in a step growth reaction. Of the variety of catalyst systems known for alkoxycarbonylation, cobalt catalysts are attractive as they (1) are robust, (2) do not require costly phosphine ligands or noble metals, which are also sensitive to irreversible reduction to elemental metal in any reaction involving $\mathrm{CO}$, and (3) are not substrate sensitive; they are reactive also towards higher alcohols other than methanol and, more importantly, internal olefins. ${ }^{9}$ Olefin isomerization is an ubiquitous reaction in the presence of transition metal compounds. While the formation of a small amount of unreacted internal olefin is unproblematic in the synthesis of small molecules, in the polymerization

Chair of Chemical Materials Science, Dept. of Chemistry,

University of Konstanz, 78464 Konstanz, Germany.

E-mail: stefan.mecking@uni-konstanz.de; Fax: + 497531885152 ;

Tel: +497531885151

+ Electronic supplementary information (ESI) available: Experimental procedures, $\mathrm{H}$ and ${ }^{13} \mathrm{C}$ NMR spectrum of polyester product. See DOI: $10.1039 / \mathrm{b} 912294 \mathrm{j}$

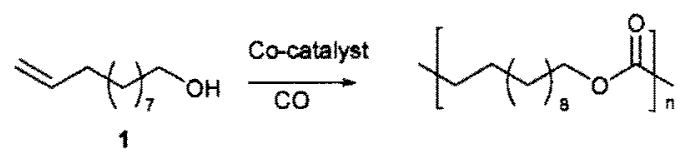

Scheme 1

reaction studied a few percent of unreactive functional groups would severely limit molecular weights.

Exposure of neat 1 to $\mathrm{CO}$ pressure at elevated temperature in the presence of catalytic amounts of $\left[\mathrm{Co}_{2}(\mathrm{CO})_{8}\right] /$ pyridine resulted in quantitative conversion to solid polymeric material (Scheme 1).

Remarkably, in view of the high functional group conversion required, and the high viscosity of polymer melts which will hamper further reaction at higher conversions, gel permeation chromatography (GPC) demonstrates the material to be higher molecular weight polymer (Fig. 1). ${ }^{1} \mathrm{H}$ NMR spectra (ESIt) acquired with a highly sensitive cryogenic coil probe enabled the quantitative observation of endgroups. A functional group conversion of up to $>99 \%$ is evident from the methylene protons of the $-\mathrm{CH}_{2} \mathrm{OH}$ endgroups (vide infra). This corresponds to degrees of polymerization $\left(\mathrm{DP}_{n}\right)$ of $>100$ (Table 1). The respective $M_{n}$ values reasonably agree with apparent $M_{\mathrm{n}}$ from GPC ws. polystyrene standards. This also demonstrates that no excessive formation of macrocyclic lactone ${ }^{10}$ occurred.

The influence of catalyst composition and reaction conditions on the polymerization reaction was studied (Table 1). The pyridine : Co ratio has a moderate but significant effect on the degree of functional group conversion and consequently molecular weight (entries 1,3 and 4). A 32-fold excess of pyridine appears optimum. In the range of pressure studied, up to 200 bar, an increased $\mathrm{CO}$ pressure favors the polymerization reaction, and promotes formation of higher molecular weight polymer. Similar to trends observed in the

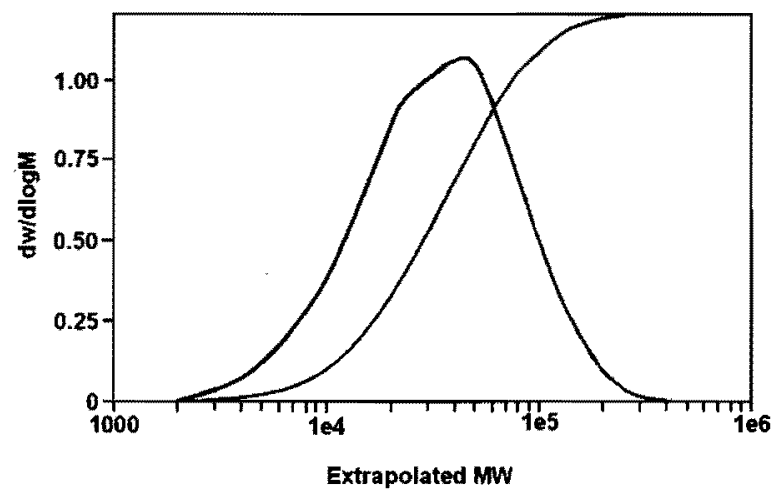

Fig. 1 GPC trace of poly(dodecyloate) (Table 1, entry 10). 


\begin{tabular}{|c|c|c|c|c|c|c|c|c|c|}
\hline Entry & Pyridine/mmol & Pyridine : Co & $P /$ bar & $T /{ }^{\circ} \mathrm{C}$ & $t / \mathrm{h}$ & $\begin{array}{l}M_{\mathrm{w}} \times 10^{4} \\
(\mathrm{GPC})^{d} / \mathrm{g} \mathrm{mol}^{-1}\end{array}$ & $\begin{array}{l}M_{\mathrm{n}} \times 10^{4} \\
(\mathrm{GPC})^{d} / \mathrm{g} \mathrm{mol}^{-1}\end{array}$ & $\mathrm{DP}_{\mathrm{n}}(\mathrm{NMR})$ & $T_{\mathrm{m}} /{ }^{\circ} \mathrm{C}$ \\
\hline 1 & 39 & $8: 1$ & 200 & 160 & 69 & 2.5 & 1.0 & 57 & $56 / 61$ \\
\hline $2^{b}$ & 11 & $8: 1$ & 200 & 160 & 64 & 0.4 & 0.2 & 12 & 55 \\
\hline 3 & 154 & $32: 1$ & 190 & 160 & 65 & 4.7 & 2.2 & 140 & $61 / 66$ \\
\hline 4 & 307 & $64: 1$ & 200 & 160 & 69 & 2.2 & 1.1 & 40 & $62 / 66$ \\
\hline 5 & 154 & $32: 1$ & 180 & 100 & 67 & n.d $f$ & $\mathrm{n} . \mathrm{d} \cdot$ & n.def & n.d ${ }^{\prime}$ \\
\hline 6 & 154 & $32: 1$ & 200 & 200 & 66 & 0.8 & 0.6 & 21 & $61 / 66$ \\
\hline 7 & 154 & $32: 1$ & 100 & 160 & 64 & 1.1 & 0.7 & 38 & $64 / 69$ \\
\hline 8 & 154 & $32: 1$ & 50 & 160 & 64 & 0.3 & 0.3 & 13 & 63 \\
\hline 9 & 154 & $32: 1$ & 200 & 160 & 16 & 2.6 & 1.3 & 50 & $63 / 70$ \\
\hline $10^{t}$ & 154 & $32: 1$ & 190 & 160 & 67 & 4.6 & 2.3 & 146 & n.d \\
\hline
\end{tabular}

${ }^{a}$ Polymerizations were performed in a $280 \mathrm{~mL}$ steel autoclave using $0.175 \mathrm{~mol}$ undecenol and $2.4 \mathrm{mmol}\left[\mathrm{Co}_{2}(\mathrm{CO})_{8}\right]{ }^{b} 50 \mathrm{mmol}$ undecenol, $25 \mathrm{~mL}$ toluene, $0.7 \mathrm{mmol}\left[\mathrm{Co}_{2}(\mathrm{CO})_{8}\right] .{ }^{c} 1.2 \mathrm{mmol}\left[\mathrm{Co}_{4}(\mathrm{CO})_{12}\right] .{ }^{d} \mathrm{In} \mathrm{THF}$ vs. polystyrene standards. ${ }^{e} 19 \%$ conversion of the functional groups. ${ }^{f}$ Not determined.

alkoxycarbonylation of 1 -olefins to small molecule products, ${ }^{9 a}$ a temperature around $160{ }^{\circ} \mathrm{C}$ appears beneficial. At $100{ }^{\circ} \mathrm{C}$ only oligomers are formed, presumably due to a slower polymerization reaction, and at $200^{\circ} \mathrm{C}$ also comparably lower molecular weight polymer was formed, likely due to catalyst decomposition. $^{9 k}$ Reaction with added solvent (toluene) resulted in lower molecular weights; the unfavorable lower concentration of functional groups apparently dominates over a conceivable increased reactivity due to higher mobility in the less viscous solution (entry 2 ). In this study, reactions were usually run for $c a .65 \mathrm{~h}$ to ensure the maximum degree of polymerization achievable. However, already after $16 \mathrm{~h}$ the reaction seems to be near completion (entry 9). $\left[\mathrm{CO}_{4}(\mathrm{CO})_{12}\right]$ as a metal source was reported to afford higher yields in the preparation of carboxylic acid esters than $\left[\mathrm{CO}_{2}(\mathrm{CO})_{8}\right],{ }^{9 \mathrm{C}}$ in our hands under the conditions of the polymerization reaction no significant difference was observed (entry 3 vs. 10).

The microstructure of a typical polymer (entry 3) was studied preliminarily by ${ }^{1} \mathrm{H}$ and ${ }^{13} \mathrm{C}$ NMR spectroscopy (ESI $\dagger$ ). Internal olefin and hydroxy endgroups are observed. A bout 20 to $30 \%$ of the repeat units are branched, as a result of 2,1-insertion of terminal olefinic moieties, or reaction of internal olefinic groups formed by isomerization. Methyl branches predominate (Fig. 2).

Impurities of monofunctional reagents limit molecular weights attainable in polycondensation reactions. The

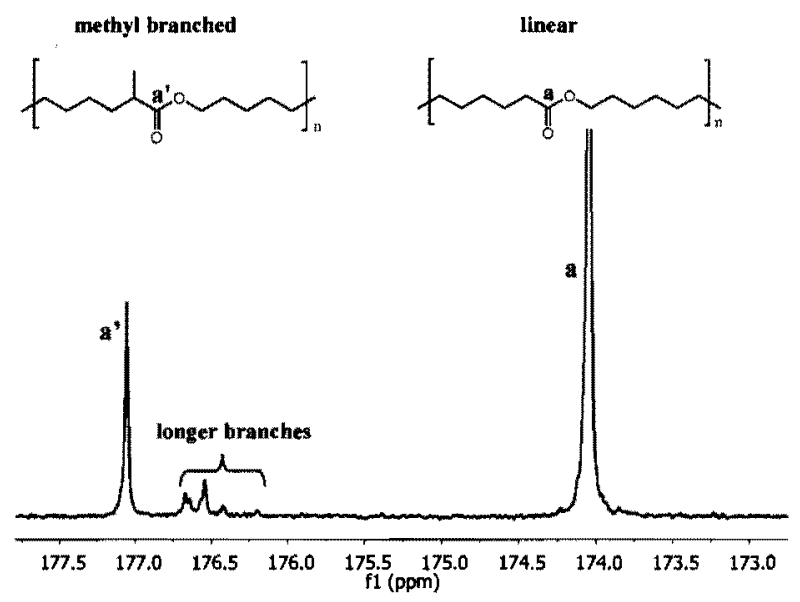

Fig. $2{ }^{13} \mathrm{C}$ NMR carbonyl resonances of the polyester undec-10 en-ol employed is ca. $99.5 \%$ pure by GC. A major impurity appears to be undecanol. Thus, while molecular weights are partly limited by incomplete functional group conversion, this monofunctional impurity also seems to contribute.

The obtained polyesters are semicrystalline with a complex melt behavior; two melting peaks occur around $65{ }^{\circ} \mathrm{C}$. A narrow crystallization transition is observed at $T_{c}$ ca. $45{ }^{\circ} \mathrm{C}$ upon cooling. Molecular weights are in a regime where the thermal properties of the polyester are independent of molecular weight (Table 1). The similar melt behavior of the different samples indicates that polymer microstructures do not differ substantially.

In conclusion, cobalt-catalyzed reaction of undec-10-en-1-ol with $\mathrm{CO}$ is a convenient route to higher molecular weight polyesters. The starting materials can be readily prepared from renewable resources. "In this entirely chemical polyester synthesis, not involving fermentation, the molecular structure of the plant oil feedstock is largely retained in the linear polyester product, which predominantly consists of hydrocarbon repeat units. An attractive challenge is the development of catalysts enabling the control of microstructures, and thus thermal properties.

We thank Lars Bolk for GPC and DSC measurements. Financial support by BASF SE is gratefully acknowledged. We thank Hans-Helmut Görtz and Tobias Steinke for fruitful discussion.

\section{Notes and references}

1 S. Mecking, Angew. Chem., Int. Ed., 2004, 43, 1078-1085 (Angew. Chem., 2004, 116, 1096-1104).

2 (a) Biopolymers, ed. Y. Doi and A. Steinbüchel, Wiley-VCH, Weinheim, 2002, vol. 3a, 3b, 4; (b) A. H. Tullo, Chem. Eng. News, 2008, 86(39), 21-25; (c) D. R. Dodds and R. A. Gross, Science, 2007, 318, 1250-1251.

3 The price of castor oil has been roughly similar to the price of crude oil, averaged over the last years. Although market prices are obviously influenced by many factors, they are an instructive indicator of the effort involved with the production of a raw material and its availability.

4 (a) U. Biermann, W. Friedt, S. Lang, W. Lühs, G. Machmüller, J, O. Metzger, M. Rüsch gen. Klaas, H. J. Schäfer and M. P. Schneider, Angew. Chem., Int. Ed., 2000, 39, 2206-2224 (Angew. Chem., 2000, 112, 2292-2310); (b) M. A. R. Meier, J. O. Metzger and U. S. Schubert, Chem. Soc. Rev., 2007, 36, 1788-1802. 
5 F. C. Naughton, J. Am. Oil Chem. Soc., 1974, 51, 65-71.

6 (a) A. Mullen, in New Syntheses with Carbon Monoxide, ed. J. Falbe, Springer, Berlin, 1980, vol. 11, pp. 243-302; (b) M. Beller and A. M. Tafesh, in Applied Homogeneous Catalysis with Organometallic Compounds, ed. B. Cornils and W. A. Herrmann, Wiley-VCH, Weinheim, 2000, pp. 178-201; (c) H. M. Colquhoun, D. J. Thompson and M. V. Twigg, Carbonylation, Plenum, New York, 199l; (d) M. Beller, B. Comils, C. D. Frohning and C. W. Kohlpaintner, J. Mol. Catal. A: Chem. $1995,104,17-85$; (e) P. W. N. M. van Leeuwen and C. Claver, in Comprehensive Coordination Chemistry II, ed. J. A. McCleverty and T. J. Meyer, Elsevier, Oxford, 2004, vol. 9, pp. 141-206.

7 (a) H. Alper and D. Leonard, J. Chem. Soc., Chem. Commun., 1985, 511-512; (b) J. Falbe, H.-J. Schulze-Steinen and F. Korte, Chem. Ber., 1965, 98, 886-893; (c) J. K. Funk, D. K. Newsham, D. N. Goldstein, S. Liu and A. Sen, J. Mol. Catal. A: Chem, 2005 239, 185-192; (d) E. Drent, Shell Oil Company, US Pat., 4960906 , 1990.
8 (a) E. Drent and A. J. M. Breed, Shell International Research, UK, GB Pat., 2226822A, 1990; (b) J. M. Penney and J. M. Boncella, Polym. Prepr. (Am. Chem. Soc., Div. Polym. Chem.), 1998, 39, 573; (c) J. M. Penney, Ph.D. Dissertation, University of Florida, 1999.

9 (a) P. Holmann, K. Kosswig and W. Schaefer, Ind. Eng. Chem. Prod. Res. Dev., 1980, 19, 330-334; (b) D. Foster, H. Van Rensburg and R. P. Tooze, Sasol Technology, WO $2008 / 023338 \mathrm{~A} 1$, $2008 ;(c)$ A. M. Lennertz, J. Laege and M. J. Mirbach, J. Organomet. Chem., 1979, 171, 203-207.

10 Formation of macrocycles in polycondensation reactions: (a) H. Jacobson and W. H. Stockmayer, J. Chem. Phys, 1950 , 18, 1600-1606; (b) P. J. Flory, U. W. Suter and M. Mutter, J. Am. Chem. Soc., 1976, 98, 5733 5739; (c) S. C. Moratti, Macromolecules, $2005,38,1520-1522$.

11 The polyester prepared can be expected to be biodegradable, based on the observed biodegradability of various other aliphatic polyesters studied to date, $c f$. ref. 1 and references cited therein. 